\title{
TINJAUAN MUTU AGGREGAT LAPISAN PONDASI BAWAH PADA PERKERASAN JALAN BATAS KOTA LHOKSEUMAWE - PANTON LABU
}

\author{
Said Jalalul Akbar ${ }^{1)}$, Mukhlis ${ }^{2)}$, Burhanuddin ${ }^{3)}$ Muhibbuddin ${ }^{4)}$ \\ Jurusan Teknik Sipil Universitas Malikussaleh \\ Email: Jaakidani@gmail.com ${ }^{1)}$ Muhibbuddin92@yahoo.com ${ }^{3)}$
}

\begin{abstract}
Abstrak
Jalan raya adalah suatu lintasan yang bertujuan untuk memindahkan manusia dan barang dari tempat asal ketujuan. Pembangunan sebuah jalan haruslah dapat menciptakan keadaan yang aman bagi pengendara dan pejalan kaki yang memakai jalan tersebut Agregat merupakan salah satu komponen utama dari struktur perkerasan jalan dan sangat berperan dalam menentukan mutu (kekuatan/ketahanan) dari jalan tersebut. Agregat terdiri darii kumpulan butir-butir batu pecah, kerikil, pasir baik yang berasal dari alam maupun buatan yang berbentuk mineral padat berupa ukuran besar maupun kecil. Dari hasil pengamatan banyak pembangunan sebuah jalan saat ini telah terjadi kerusakan tetapi masih dalam umur rencana. Penelitian ini bertujuan ingin melihat mutu agregat yang digunakan pada jalan tersebut dan kemudian membandingkan hasil pemeriksaan yang dilakukan dilaboratorium dengan hasil pemeriksaan yang dilakukan oleh kontraktor (pelaksana). Adapun metode yang digunakan pada penelitian ini yaitu metode Bina Marga. Dari hasil pemeriksaan yang telah dilakukan di laboratorium dan oleh kontraktor pelaksana untuk pengujian sifat fisis agregat keduanya telah memenuhi persyaratan sesuai yang telah ditetapkan oleh Direktorat Jenderal Bina Marga. Adapun yang membedakan hanya pada variasi persen lolos saringan saja. Dari hasil pengujian keseluruhannya dapat dikatakan bahwa mutu agregat hasil pemeriksaan yang dilakukan di laboratorium Universitas Malikussaleh lebih baik bila dibandingkan dengan mutu agregat hasil pemeriksaan yang dilakukan oleh kontraktor pelaksana
\end{abstract}

Kata kunci :Agregat, , Mutu Agregat, LPB

\section{Pendahuluan}

Jalan raya adalah suatu lintasan yang bertujuan untuk memindahkan objek (manusia, hewan dan barang) dari suatu tempat ketempat yang lain. Kekuatan struktur jalan sangat dipengaruhi oleh faktor mutu agregat yang digunakan. Agar konstruksi jalan dapat melayani arus lalu-lintas sesuai dengan umur rencana, maka perlu perencanaan perkerasan yang baik. Dari hasil pengamatan di lapangan banyak kontruksi jalan mengalami kerusakan padahal masih dalam batas waktu umur rencana. Hal ini banyak penyebabnya, dan salah satu faktor tersebut adalah mutu dari agregat yang digunakan. Dalam penelitian ini ingin diketahui khususnya yang berhubungan dengan mutu agregat (Lapis Pondasi Bawah).

Lapisan perkerasan jalan terdiri dari tanah dasar, lapisan pondasi bawah (Sub Base Course), lapisan pondasi atas (Base Course). Bahan baku yang umum digunakan sebagai bahan perkerasan jalan raya adalah bahan agregat (pasir, kerikil, batu koral dan batu pecah). bahan pengikat (aspal), bahan pengisi/filler (semen portland) serta bahan additive kalau diperlukan. Untuk memperoleh jenis perkerasan yang berkualitas baik dan tahan lama tergantung pada cara pembuatan atau mengolah dan melakukan uji kelayakan yang mengacu kepada spesifikasi 
yang ada. Penelitian ini menggunakan metode Bina Marga yang mengacu pada Standar Nasional Indonesia (SNI) untuk perencanaan lentur jalan. Penelitian ini bertujuan membandingkan hasil pemeriksaan mutu agregat yang dilakukan di laboratorium dengan hasil pemeriksaan mutu agregat yang dilakukan oleh kontraktor/pelaksana lapangan.

\section{Tinjauan Kepustakaan}

\subsection{Agregat}

Oglesby dan Hick (1982) menyatakan bahwa bahan yang paling umum untuk lapisan jalan dan strukturnya adalah batu pecah, batu kerikil yang dipecah dan pasir. Menurut Sukirman (1999), berdasarkan besar atau ukurannya agregat dapat dibedakan atas:

- Agregat kasar, yaitu agregat yang ukurannya $>4,75 \mathrm{~mm}$ menurut ASTM atau agregat yang ukurannya $>2 \mathrm{~mm}$ menurut ASSHTO

- Agregat halus, yaitu agregat yang ukurannya $<4,75 \mathrm{~mm}$ menurut ASTM atau agregat yang ukurannya $<2 \mathrm{~mm}$ dan $>0,075 \mathrm{~mm}$ menurut ASSHTO

- Abu Batu atau filler, yaitu agregat halus yang umumnya lolos saringan \# 200

Menurut Krebs dan Walker (1971), gradasi merupakan kunci utama dari sifat-sifat agregat. Berbagai macam metode dalam menyatakan distribusi ukuran agregat telah ditemukan. Salah satu dari metode tersebut adalah dengan menggunakan Rumus Fuller yaitu:

$$
P=100(d / D)^{n}
$$

di mana :

$\mathrm{P}=$ Persen lolos saringan

$\mathrm{d}=$ Ukuran agregat yang sedang diperhitungkan

$\mathrm{D}=$ Ukuran maksimum dari agregat

$\mathrm{n}=$ Koefisien $(0,45-0,5$ untuk gradasi menerus $)$

Menurut Sukirman (1992) ketahanan agregat terhadap penghancuran (degradasi) diperiksa dengan menggunakan percobaan Abrasi Los Angeles (Abrasion Los Angeles Test)

\subsubsection{Agregat Kasar}

Agregat dapat diartikan sebagai kerikil yang utuh, agregat kasar yang berasal dari kerikil, kerikil pecah atau sebagai yang terdiri dari kerikil pecah dengan kombinasi kerikil utuh yang berukuran rata-rata 1,5-2 inci. Berat jenis agregat kasar adalah perbandingan berat volume agregat tanpa mengandung rongga terhadap berat air pada volume yang sama. Absorbsi merupakan persentase perbandingan berat air yang diserap oleh agregat pada keadaan kering air permukaan dengan berat agregat pada keadaan kering oven. Hubugan antara berat jenis dengan daya serap adalah jika semakin tinggi nilai berat jenis agregat maka akan semakin kecil daya serap air tersebut. Berat volume agregat yang baik untuk material adalah dengan nilai lebih basar dari 1560 kg/liter dan 1400 kg/liter.

\subsubsection{Agregat Halus}

Agregat halus (Pasir) yang baik mempunyai berat jenis lebih besar dari pada $2,6 \%$. Berat jenis dalam keadaan jenuh kering permukaan dihitung dengan 
persamaan:

$$
B J . S S D=\frac{D}{B+D-C}
$$

di mana:

$\mathrm{B}=$ Picnometer + Kaca yang berisi air $(\mathrm{gr})$

$\mathrm{C}=$ Picnometer + Pelat kaca + Benda Uji dan Air (gr)

$\mathrm{D}=$ Benda uji Kondisi Jenuh Kering Permukaan (gr)

Berat jenis pasir dalam kering oven dapat dihitung dengan persamaan:

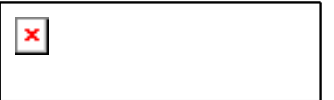

di mana:

$$
\begin{aligned}
& \text { A }=\text { Benda Uji Kering Oven (gr) } \\
& B=\text { Picnometer }+ \text { kaca yang berisi Air (gr) } \\
& \text { D = Benda uji Kondisi Jenuh Kering Permukaan (gr) }
\end{aligned}
$$

Untuk penyerapan air pada pasir dapat dihitung dengan persamaan :

$$
W a=\frac{D-A}{A} \times 100 \%
$$

di mana:

$$
\begin{aligned}
& \mathrm{A}=\text { Benda Uji Kering Oven }(\mathrm{gr}) \\
& \mathrm{D}=\text { Benda uji Kondisi Jenuh Kering Permukaan (gr) } \\
& \mathrm{Wa}=\text { adalah penyerapan air }
\end{aligned}
$$

Pengujian tersebut diperoleh berat isi agregat kasar dan agregat halus dapat dihitung dangan persamaan:

$$
\text { Berat isi }=\frac{C-A}{V}
$$

di mana:

$\mathrm{C}=$ Berat Agregat $(\mathrm{gr})$

$\mathrm{A}=$ Berat Container $(\mathrm{gr})$

$\mathrm{V}=$ Volume Container $\left(\mathrm{cm}^{3}\right)$

\subsection{Sifat-sifat campuran lapis pondasi agregat}

Lapis pondasi agregat setelah dipadatkan harus memenuhi sifat-sifat yang ditunjukkan dalam Tabel 1

Tabel 1 Ketentuan Sifat Lapis Pondasi Agregat

\begin{tabular}{|l|l|}
\hline Sifat & Kelas B \\
\hline Abrasi dari agregat kasar (SNI 03-2417-2008) & Mak. 40\% \\
\hline Indeks plastis (SNI 1966:2008) & Mak. 10 \\
\hline Hasil kali indeks plastisitas dengan \% lolos saringan No.200 & - \\
\hline Batas cair (SNI 03-1967-2008) & Mak. 35 \\
\hline $\begin{array}{l}\text { Gumpalan lempung dan butir-butir mudah pecah dalam agregat (SNI 03- } \\
\text { 4141-1996) }\end{array}$ & Mak. 5\% \\
\hline CBR (SNI 03-1744-1989) & Min. 50\% \\
\hline Perbandingan persen lolos \#200 dan \#40 & Mak. 2/3 \\
\hline \multicolumn{2}{|l}{ Sumber: Kementerian Pekerjaan Umum Direktorat Jenderal Bina Marga } \\
(spesifikasi umum 2010).
\end{tabular}

Tinjauan Mutu Aggregat Lapisan Pondasi Bawah Pada Perkerasan Jalan Batas Kota Lhokseumawe-Panton Labu - Said Jalalul Akbar 


\subsection{Persyaratan Agregat dan Campuran Agregat}

Persyaratan agregat dalam campuran agregat haruslah memenuhi kriteria Kementerian Pekerjaan Umum Direktorat Jenderal Bina Marga, Spesifikasi Umum 2010:

1. Agregat Kasar

a. Agregat kasar (tertahan pada ayakan $4,75 \mathrm{~mm}$ ) harus terdiri atas partikel yang keras dan awet.

b. Agregat kasar kelas A yang berasal dari batu kali harus $100 \%$ mempunyai paling sedikit satu bidang pecah.

c. Agregat kasar kelas B yang berasal dari batu kali harus $50 \%$ mempunyai paling sedikit satu bidang pecah.

2. Fraksi Agregat Halus

Agregat halus (lolos ayakan $4,75 \mathrm{~mm}$ ) harus terdiri atas partikel pasir atau batu pecah halus. Pengujian agregat diperlukan untuk mengetahui karakteristik fisik dan mekanik agregat sebelum digunakan sebagai bahan lapis pondasi.

3. Gradasi Agregat Campuran/Gabungan

Agregat untuk lapis pondasi harus bebas dari bahan organic dan gumpalan lempung atau bahan-bahan lain yang tidak dikehendaki, harus memenuhi persyaratan gradasi agregat campuran/gabungan yang disajikan pada tabel diatas:

\subsection{Agregat Lapisan Pondasi bawah (SubBase Course)}

Pada lapisan pondasi bawah (subbase course) umumya menggunakan agregat kelas B. Untuk agregat kasar terdiri atas batu pecah atau kerikil yang keras dan awet. Untuk lapis pondasi agregat kelas B diperlukan agregat kasar yang mempunyai paling sedikit satu bidang pecah. Sedangkan untuk agregat halus dapat berupa abu batu dan pasir. Agregat campuran merupakan gabungan dari agregat kasar dan halus. Untuk mendapatkan agregat gabungan bisa dilakukan dengan cara analitis maupun grafis. Campuran kombinasi agregat minimum terdiri atas 2 (dua) fraksi yaitu fraksi kasar dan fraksi halus. Pencampuran bahan untuk memenuhi ketentuan yang disyaratkan harus dikerjakan dilokasi instalasi pemecah batu atau pencampur. Pencampuran bahan ini menggunakan pemasok mekanis yang telah dikalibrasi untuk memperoleh aliran yang menerus dari komponenkomponen campuran dengan proporsi yang benar. Dalam keadaan apapun tidak dibenarkan melakukan campuran dilapangan. Seluruh lapis pondasi agregat harus bebas dari bahan organik, gumpalan lempung atau bahan-bahan yang tidak dikehendaki lainnya.

\subsection{Mutu dan Sifat Agregat}

Mutu dan sifat agregat merupakan salah satu faktor penentu kemampuan perkerasan jalan dalam memikul beban lalu lintas. Disamping itu mutu dan sifat agregat juga merupakan faktor penting dalam menentukan daya tahan terhadap cuaca. Oleh karena itu sebelum diputuskan suatu agregat dapat digunakan sebagai material perkerasan jalan, diperlukan pemeriksaan yang teliti untuk mencapai hasil yang maksimal. Karakteristik tersebut tidak semua dipakai untuk penerapan pembuatan jalan. Contoh, agregat untuk lapis pondasi jalan (subbase course) tidak mensyaratkan keausan dan tahann abrasi yang tinggi, tetapi hal tersebut sangat penting untuk bahan lapis permukaan. 


\subsection{Tinjauan Mutu Terhadap Kinerja Pekerasan Lentur Jalan Raya}

Jaringan jalan nasional dan propinsi sering mengalami kerusakan struktural sebelum umur layanan selesai, kondisi ini memunculkan pertanyaan mendasar tentang bagaimana sesungguhnya pemberlakuan pengendalian kualitas perkerasan jalan. Kerusakan tersebut dievaluasi karena pengaruh air dan beban kendaraan berlebih, sementara itu fakta dilapangan menunjukkan bahwa kegagalan dilapangan disebabkan tidak tercapainya kualitas pelaksanaan sesuai dengan standar mutu yang ada. Berbagai pengalaman empirik menyatakan bahwa kegagalan mutu perkerasan jalan dapat disebabkan oleh banyak hal, antara lain kesalahan perencanaan dan desain perkerasan, ketidaksesuain pelaksanaan konstruksi perkerasan terhadap spesifikasi teknis, ketidaksesuaian laporan administrasi proyek terhadap fakta dilapangan, dan ketidaktepatan pengendalian mutu pelaksanaan pekerjaan terhadap standar mutu yang digunakan. Hasil penelitian menunjukkan bahwa terdapat 5 (lima) faktor dominan yang signifikan mempengaruhi pemberlakuan tinjauan mutu atau standar mutu secara sistematik yaitu sumber daya manusia, sosialisasi standar mutu, pencapaian mutu, kekuatan struktural dan kemantapan jalan.

Perkerasaan lentur jalan memiliki beberapa lapisan pondasi, setiap pondasi memiliki indicator teknik mutunya.Untuk lapis permukaan (surface course) yaitu tingkat kepadatan yang merupakan perbandingan antara kepadatan lapangan dengan kepadatan laboratorium. Kepadatan minimal 95\% terhadap kepadatan laboratarium atau tingkat kepadatan minimal agar mutu lapisan permukaan dapat diterima jika lebih besar dari $95 \%$. Untuk lapis pondasi bawah(Sub Base Course) nilai CBR dilapangan disyaratkan $80 \%$, nilai kepadatan lapangan minimal 90\% dari kepadatan maksimum laboratarium, dan nilai kadar air dilapangan berada pada rentang toleransi $2 \%$ terhadap kadar air optimum di laboratarium. Untuk tanah dasar (subgrade) antara lain : nilai CBR dilapangan disyaratkan lebih besar atau sama dengan 90\% dari CBR laboratorium, nilai kepadatan lapangan disyaratkan lebih besar atau sama dengan $95 \%$ dengan kepadatan laboratorium, dan nilai kadar air lapangan berada pada toleransi $2 \%$ terhadap nilai kadar air optimum (Kementerian Pekerjaan Umum Direktorat Jenderal Bina Marga, Spesifikasi Umum 2010) :

\subsection{Faktor Pemberlakuan Standar Mutu Perkerasaan Lentur Jalan}

Pemberlakuan standar mutu diperlakukan sebagai suatu proses yang berlangsung secara terus-menerus yang berkelanjutan, artinya proses pemantauan, pengawasan, penilaian, dan evaluasi implementasi standar mutu harus dilakukan sejak tahapan konstruksi sampai pasca konstruksi. Pemberlakuan standar mutu memerlukan monitoring dan evaluasi terhadap faktor-faktor yang mempengaruhinya sehingga dapat diketahui pada bagian mana faktor yang kuat dan lemah, kemudian dapat dirumuskan solusinya. Faktor dimaksudkan keadaan atau peristiwa yang mempengaruhi terjadinya sesuatu atau sesuatu yang secara berkontribusi terhadap suatu penyelesaian, hasil dan proses.

\subsection{Spesifikasi Teknik Perencanaan, Pelaksanaan Dan Pengendalian Mutu Lapis Pondasi Agregat}

Lapisan Pondasi merupakan bagian perkerasan jalan raya yang terletak antara lapis permukaan jalan dan tanah dasar, dimana salah satu fungsi utamanya 
pada perkerasan lentur adalah untuk menyebarkan beban kendaraan agar tegangan yang sampai ke tanah dasar tidak melampaui tegangan yang dapat menimbulkan deformasi berlebih. Atas pertimbangan efisiensi bahan lapis pondasi terdiri atas dua bagian yaitu lapis pondasi atas dan lapis pondasi bawah.Karena letaknya yang lansung dibawah lapis permukaan sehingga menerima tegangan yang besar akibat beban roda kendaraan, maka lapis pondasi atas dan lapis pondasi bawah pada perkerasan lentur harus mempunyai ketahanan yang tinggi terhadap deformasi. Karena posisinya yang terletak di bawah lapis pondasi atas, maka lapis pondasi bawah mempunyai mutu yang dapat lebih rendah dari pada mutu untuk lapis pondasi atas. Lapis pondasi atas pada perkerasan lentur biasanya terdiri atas lapisan hasil pemadatan batu pecah, kerikil atau slag yang bergradasi tertentu, atau bahan hasil stabilisasi; sedangkan lapis pondasi bawah dapat terdiri atas bahan yang sama seperti untuk lapis pondasi, tetapi dengan mutu yang lebih rendah. Untuk mencegah terjadinya keruntuhan akibat tegangan yang terjadi langsung di bawah lapis pondasi atas harus terdiri dari bahan yang bermutu tinggi. Apabila lapis pondasi atas terdiri atas agregat, maka fraksi agregat tersebut harus sesuai dengan gradasi yang dicantumkan dalam spesifikasi.

Tabel 2 Gradasi Lapis Pondasi Agregat

\begin{tabular}{|l|l|l|l|}
\hline \multicolumn{2}{|c|}{ Ukuran Ayakan } & \multicolumn{2}{c|}{ Persen Berat Yang Lolos } \\
\hline \multicolumn{1}{|c|}{ ASTM } & \multicolumn{1}{c|}{ Kelas A } & \multicolumn{1}{c|}{ Kelas B } \\
\hline $2^{\prime}$ & 50 & 100 & 100 \\
\hline $1 \frac{\mathrm{m}}{2} \mathrm{\prime}$ & 37,5 & $79-85$ & $88-95$ \\
\hline $1^{\prime}$ & 25,0 & $44-58$ & $70-85$ \\
\hline $3 / 4$ & 9,50 & $29-44$ & $30-65$ \\
\hline No. 4 & 4,75 & $17-30$ & $25-55$ \\
\hline No. 10 & 2,0 & $7-17$ & $15-40$ \\
\hline No. 40 & 0,425 & $2-8$ & $8-20$ \\
\hline No. 200 & 0,075 & $2-8$ \\
\hline
\end{tabular}

Sumber: Kementerian Pekerjaan Umum Direktorat Jenderal Bina Marga (spesifikasiumum 2010).

\subsection{Pemadatan Standar Proctor}

Bukhari dkk (2004), Ada dua macam pengujian pemadatan, yaitu pengujian pemadatan Proctor standar dan pengujian pemadatan proctor modifikasi (modified proctor). Uji standar proctor dilakukan untuk mencari kadar air optimum yang menjadi acuan kepadatan agregat maksimum. Untuk menghitungnya digunakan rumus:

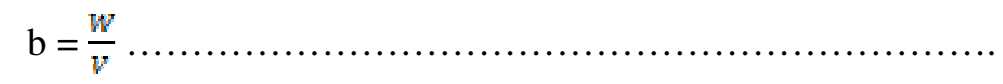

di mana:

$\mathrm{W}=$ Berat agregat yang dipadatkan pada cetakan

$\mathrm{V}=$ Volume cetakan $\left(\mathrm{cm}^{3}\right)$

\subsection{Analisa CBR (California Bearing Ratio)}

Sukirman (1999), menyatakan CBR adalah perbandingan antara beban yang dibutuhkan untuk penetrasi contoh tanah sebesar 0,1 "/0,2" dengan beban yang ditahan batu pecah standar pada penetrasi 0,1 "/0,2" tersebut. Harga CBR 
dinyatakan dalam persen. Jadi harga CBR adalah nilai yang menyatakan kualitas tanah dasar di bandingkan dengan bahan standar berupa batu pecah yang mempunyai nilai CBR sebesar $100 \%$ dalam memikul beban lalu lintas. CBR Lapangan sering disebut CBR inplace atau field CBR yang gunanya untuk

\section{Metode Penelitian}

\subsection{Pemeriksaan Sifat Fisis Agregat}

Sebelum agregat digunakan sebagai material sub base course, maka terlebih dahulu dilakukan pemeriksaan terhadap sifat- sifat fisis yang akan meliputi antara lain: berat jenis, analisa saringan, berat isi agregat, pemadatan proktor dan pemadatan CBR.

\subsection{Pengukuran Berat Jenis}

Menurut (SNI 1970: 2008) berat jenis adalah perbandingan antara berat dari suatu volume dari material terdapat berat air dengan volume yang sama pada temperatur yang ditentukan. Pengukuran berat jenis dan absorbsi yang dilakukan berdasarkan American Concrete instituten (ACI).

Peralatan yang digunakan timbangan kapasitas 1500 gram, oven, keranjang besi, ember, baskom dan kain lab. Kerikil yang diambil secara acak, kemudian direndam selama 2 jam agar jenuh. Agregat yang telah jenuh air kemudian dikeringkan permukaannya dengan cara berbalik agar pengeringannya merata. Untuk agregat halus, keadaan kering permukaan (SSD) diketahui dengan cara uji pasir yang dimasukan ke dalam konis pasir tiga lapisan yang tebalnya relatif sama. Masing - masing lapisan dipadatkan dengan menggunakan tongkat besi sebanyak 25 kali tumbukan. Setelah permukaan pasir diratakan lalu konis pasir. diangkat secara vertikal keatas. Keadaan kering permukaan ditunjukan dengan runtuhnya sebagian agregat. Sejumlah pasir jenuh air permukaan selanjutnya dimasukan kedalam gelas/toples dan ditimbang beratnya. Gelas kemudian diisi penuh dengan air bersih, Gelas ditutup dengan kaca yang rapat, lalu gelas dibalikbalik beberapa kali sehingga semua udara dalam pasir keluar. Setelah udara keluar semuanya dari pasir jenuh air, maka gelas bersarta pasir, air dan penutupnya ditimbang, kemudian dilanjutkan dengan menimbang gelas,air, dan penutupnya saja. Berat jenis agregat perbandingan berat jumlah volume agregat tanpa mengandung rongga udara terhadap berat air pada volume yang sama. Untuk memperoleh berat kering oven, maka air pada agregat tersebut dibuang dan agregat dioven selama 24 jam dengan temperatur $105 \pm 50^{\circ} \mathrm{C}$ lalu ditimbang.

\subsection{Analisa Saringan (Sieve Analisis)}

Pemeriksaan susunan butiran agregat dilakukan terhadap agregat halus sebanyak 1500 gram dan agregat kasar sebayak 2000 gram. Agregat tersebut diambil dari tumpukan secara acak. Sampel tersebut dimasukan kedalam susunan saringan lalu disaring dengan menggunakan saringan Testing Machine. Urutan ukuran saringan digunakan 2', 1 11/2', 3/8', No. 4, No. 10, No. 40, dan No. 200. Sampel yang tertinggal diatas ditimbang.

\subsection{Berat Isi Agregat}

Pemeriksaan bobot isi agregat kasar dan agregat halus untuk mengetahui berat isi atau bobot isi agregat halus dalam kondisi lepas dan padat. Prosedur 
pengujian persiapan contoh agregat kasar tertahan saringan No. 4 dan agregat halus lolos saringan No.4. Container diukur diameternya dan tingginya untuk diketahui volume dari container tersebut. Kemudian timbang container dalam keadaan kosong (A). Pemeriksaan bobot isi agregat kasar lepas, masukan agregat kasar jatuh bebas ke dalam container, kemudian kelebihan agregat kasarnya diratakan. Timbang container ditambah agregat kasar (B). Untuk pemeriksaan isi agregat halus padat sama seperti berat isi agregat kasar, container diukur diameter dan tingginya untuk diketahui volumenya terus ditimbang berat container kosong. Kemudian container ditusuk dengan alat tusuk, setelah ditusuk ratakan agregatnya dan kemudian ditimbang, berat container ditambah agregat halus (B).

\subsection{Pemadatan Standar Proktor}

Uji standar proctor dilakukan untuk mencari kadar air optimum yang menjadi acuan kepadatan agregat maksimum.

\section{Hasil dan Pembahasan}

Pemeriksaan material ini dilakukan untuk mengetahui sifat fisis dari material tersebut, yang merupakan juga parameter untuk mengukur atau menetukan mutu dari material yang akan digunakan dalam perencanaan campuran job mix design. Pemeriksaan agregat meliputi analisa saringan agregat, berat jenis agregat dan berat isi agregat. Hasil pemeriksaan analisa saringan laboratorium diperlihatkan pada tabel 3. Sedangkan hasil analisa saringan yang dikerjakan kontraktor pelaksana juga diperlihatkan pada tabel 4.

Tabel 3 Analisa Saringan Laboratoriom

\begin{tabular}{|c|c|c|c|c|c|c|c|}
\hline \multicolumn{2}{|c|}{ Bahan tercampur } & & & & \multicolumn{3}{|c|}{ Berat Agregat Kering $=1500$ gram } \\
\hline Ayakan & Ukuran & \multirow{2}{*}{$\begin{array}{c}\text { berat } \\
\text { saringan }\end{array}$} & \multirow{2}{*}{$\begin{array}{c}\text { berat } \\
\text { saringan } \\
+ \text { tanah }\end{array}$} & \multicolumn{2}{|c|}{ Berat tertahan } & \multirow{2}{*}{$\begin{array}{c}\text { Persen } \\
\text { Komulatif }(\%)\end{array}$} & \multirow{2}{*}{$\begin{array}{c}\text { Persen } \\
\text { Lolos }(\%)\end{array}$} \\
\hline No & $(\mathrm{mm})$ & & & ( Gram ) & $\%$ & & \\
\hline $2 "$ & 50,80 & 412 & 412 & 0,000 & 0,00 & 0,00 & 100,00 \\
\hline $11 / 2^{\prime \prime}$ & 38,10 & 500,5 & 598,5 & 98,00 & 6,53 & 6,53 & 93,47 \\
\hline $1 "$ & 25,40 & 619 & 908 & 289,00 & 19,27 & 25,80 & 74,20 \\
\hline $3 / 8^{\prime \prime}$ & 9,52 & 432 & 865,5 & 433,50 & 28,90 & 54,70 & 45,30 \\
\hline No. 4 & 4,75 & 419,5 & 540,5 & 121,00 & 8,07 & 62,77 & 37,23 \\
\hline No. 10 & 2,00 & 374 & 458 & 84,00 & 5,60 & 68,37 & 31,63 \\
\hline No. 40 & 0,42 & 386,5 & 610,00 & 223,50 & 14,90 & 83,27 & 16,73 \\
\hline No. 200 & 0,074 & 337 & 541,00 & 204,00 & 13,60 & 96,87 & 3,13 \\
\hline Pan & 0,075 & 413 & 458,50 & 45,50 & 3,03 & 99,90 & 0,10 \\
\hline jumlah & & & & 1500,00 & & & \\
\hline
\end{tabular}

Tabel 4 Analisa Saringan Pelaksana

\begin{tabular}{|c|c|c|c|c|c|}
\hline \multicolumn{2}{|c|}{ Bahan Tercampur } & \multicolumn{2}{|c|}{ Berat Agregat Kering } & 5221,8 & gram \\
\cline { 1 - 2 } Ayakan & Ukuran & \multirow{2}{*}{ Tertahan saringan } & \multirow{2}{*}{ Jumlah Tertahan } & \multirow{2}{*}{ Persen Tertahan } & Persen lewat \\
\cline { 1 - 2 } No & $(\mathrm{mm})$ & & & & 100 \\
\hline $2^{\prime \prime}$ & 50,80 & & 412,90 & 7,91 & 92,09 \\
\hline $11 / 2^{\prime \prime}$ & 38,10 & & & 23,71 & 76,29 \\
\hline & & & 1238,0 & 49,02 & 50,93 \\
\hline $1^{\prime \prime}$ & 25,40 & & 2559,7 & 63,52 & 36,48 \\
\hline $3 / 8 "$ & 9,52 & & 3316,9 & 74,07 & 25,93 \\
\hline No. 4 & 4,75 & & 3868,0 & 86,75 & 13,25 \\
\hline No. 10 & 2,00 & & 4530,1 & 97,97 & 2,03 \\
\hline No. 40 & 0,42 & & 5115,7 & & \\
\hline No. 200 & 0,074 & & & & \\
\hline
\end{tabular}


Dari perbandingan kedua tabel hasil analisa saringan di atas terlihat bahwa hasil pemeriksaan laboratorium dan hasil analisa saringan yang dilakukan oleh pelaksana keduanya telah memenuhi persyaratan spesifikasi untuk agregat pondasi bawah yang ditetapkan oleh Direktorat Jenderal Bina Marga. Adapun yang berbeda hanya besaran persen lolos, namun demikian masih dalam batas yang disyaratkan.

Tabel 5 Berat Jenis Agregat Halus serta Perbandingan Lab. Dan Pelaksana

\begin{tabular}{||c|l|r|r|r|r|c|c|c|}
\hline \hline \multicolumn{2}{|c|}{} & \multicolumn{5}{|c|}{ Lab } & \multicolumn{2}{c|}{ Pelaks } \\
\hline \hline No. & \multicolumn{1}{|c|}{ Uraian } & & I & II & III & $\begin{array}{c}\text { rata- } \\
\text { rata }\end{array}$ & \multicolumn{1}{c|}{ I } & II \\
\hline 1 & Berat Benda Uji Kering Jenuh & (SSD) & 500 & 500 & 500 & 500 & 500 & 500 \\
\hline 2 & Berat Benda Uji Kering Oven & Bk & 493,6 & 489 & 487,5 & 490 & 487,6 & 487,7 \\
\hline 3 & Berat Piknometer + air & B & 2317 & 2317 & 2317 & 2317 & 666,7 & 667,7 \\
\hline 4 & Berat Piknometer + benda uji +air & Bt & 2632 & 2621 & 2631 & 2628 & 972,3 & 973,2 \\
\hline
\end{tabular}

Tabel 6 Berat Jenis Agregat Halus, Dan Perbandingan Lab. Dan Pelaksana

\begin{tabular}{|c|c|c|c|c|c|c|c|c|c|}
\hline & & & \multicolumn{3}{|c|}{ Lab. } & \multicolumn{2}{|l|}{$\begin{array}{l}\text { Pela } \\
\text { ks }\end{array}$} & Lab. & Pelaks \\
\hline No. & \multicolumn{2}{|c|}{ Uraian } & I & II & III & I & II & rata-rata & $\begin{array}{l}\text { rata- } \\
\text { rata }\end{array}$ \\
\hline 1 & Berat Jenis Bulk & $\frac{\mathrm{B} x}{\mathrm{~B}+50 \mathrm{j}-\mathrm{Bt}}$ & 2,668 & 2,495 & 2,621 & 2,51 & 2,51 & 2,595 & 2,51 \\
\hline 2 & $\begin{array}{l}\text { Berat Jenis } \\
\text { Kering } \\
\text { Permukaan } \\
\text { Jenuh }\end{array}$ & $\frac{500}{\mathrm{~B}+500-\mathrm{Bt}}$ & 2,703 & 2,551 & 2,688 & 2,57 & 2,57 & 2,647 & 2,57 \\
\hline 3 & $\begin{array}{l}\text { Berat Jenis } \\
\text { Semu } \\
\text { (Apparent) }\end{array}$ & $\frac{\mathrm{Bk}}{\mathrm{B}+\mathrm{Bk}-\mathrm{Bt}}$ & 2,764 & 2,643 & 2,810 & 2,68 & 2,68 & 2,739 & 2,68 \\
\hline 4 & $\begin{array}{l}\text { Penyerapan Air } \\
\text { (absorbsi) }(\%)\end{array}$ & $\frac{50 \mathrm{H}-\mathrm{Bk}}{\mathrm{Bk}} \times 1004$ & $1,297 \%$ & $2,249 \%$ & $2,564 \%$ & 2,52 & 2,52 & $2,036 \%$ & 2,53 \\
\hline
\end{tabular}

Tabel 7 Hasil Pengujian Proctor Dan Perbandingan Lab. Dengan Pelaksana

\begin{tabular}{|c|c|c|c|c|c|c|c|c|c|c|c|c|}
\hline \multicolumn{8}{|c|}{ Lab } & \multicolumn{5}{|c|}{ Pelaks } \\
\hline Uraian & & & $\mathbf{I}$ & II & III & IV & $\mathbf{V}$ & $\mathbf{I}$ & II & III & IV & $\mathbf{V}$ \\
\hline Diameter Mold & $\mathrm{D}$ & $\mathrm{cm}$ & 15,6 & 15,6 & 15,6 & 15,6 & 15,6 & 15,40 & 15,40 & 15,40 & 15,40 & 15,40 \\
\hline Tinggi Mold & $\mathrm{H}$ & $\mathrm{cm}$ & 12 & 12 & 12 & 12 & 12 & 12 & 12 & 12 & 12 & 12 \\
\hline $\begin{array}{l}\text { Penambahan } \\
\text { Air }\end{array}$ & & $\%$ & 2 & 4 & 6 & 8 & 10 & 2 & 4 & 6 & 8 & 10 \\
\hline $\begin{array}{l}\text { Penambahan } \\
\text { Air }\end{array}$ & & $\mathrm{cc}$ & 120 & 240 & 360 & 480 & 600 & 120 & 240 & 360 & 480 & 600 \\
\hline spesific grafity & & $\mathrm{cm}$ & 2,62 & 2,62 & 2,62 & 2,62 & 2,62 & 2,58 & 2,58 & 2,58 & 2,58 & 2,58 \\
\hline
\end{tabular}

Berdasarkan Tabel 5 di atas terlihat bahwa hasil pemeriksaan laboratorium berat jenis agregat halus lebih mendekati spesifikasi (lebih baik) di bandingkan hasil kontraktor pelaksana. Sedangkan pada tabel 6, hasil keduanya telah memenuhi sesuai spesifikasi yang telah disyaratkan Direktorat Jenderal Bina Marga. Adapun hasil Pengujian Keausan Agregat dengan Mesin Abrasi Los 
Angeles diperoleh nilai keausan sebesar 17,620\%. Sedangkan hasil nilai keausan yang didapat oleh pelaksana sebesar $22,330 \%$. Kedua nilai tersebut berarti masih dalam batas memenuhi syarat, karena nilai maksimum keausan yang disyaratkan untuk lapisan pondasi bawah adalah $<50 \%$.

Hasil Pengujian Proctor dan perbandingan antara Laboratorium dengan Pelaksana pada tabel diatas keduanya terlihat baik (memenuhi spesifikasi), Hal ini menandakan perlakuan pemeriksaan saat pengetesan telah sama-sama baik dikerjakan. Dari hasil pengujian ini sebenarnya sudah mulai tergambar apakah agregat yang digunakan pada suatu pekerjaan termasuk kedalam katagori agregat bermutu baik.

Tabel 8 Berat Isi Dan Perbandingan Lab. Dengan Pelaksana

\begin{tabular}{|c|c|c|c|c|c|c|c|c|c|c|}
\hline Berat Isi & \multicolumn{5}{|c|}{$\mathrm{Lab}$} & \multicolumn{5}{|c|}{ Pelaks } \\
\hline Uraian & I & II & III & IV & $\mathrm{V}$ & I & II & III & IV & $\mathrm{V}$ \\
\hline $\begin{array}{l}\text { Berat tanah } \\
\text { basah + } \\
\text { Cetakan (gr) }\end{array}$ & 10189,5 & 10464,5 & 10631,5 & 10778,5 & 10784,5 & 7524, & 7705 & 789,00 & 7838 & 7733 \\
\hline $\begin{array}{l}\text { Berat } \\
\text { Cetakan (gr) }\end{array}$ & 5746,5 & 5746,5 & 5746,5 & 5746,5 & 5746,5 & 2795,8 & 2795,8 & 2795,8 & 2795,8 & 2795,8 \\
\hline $\begin{array}{l}\text { Berat tanah } \\
\text { basah(gr) }\end{array}$ & 4443 & 4718 & 4885 & 5032 & 5038 & 4728,2 & 4909,2 & 5094,2 & 5042,2 & 4937,2 \\
\hline $\begin{array}{l}\text { Isi cetakan ( } \\
\left.\mathrm{Cm}^{3}\right)\end{array}$ & 2293,61 & 2293,61 & 2293,61 & 2293,61 & 2293,61 & 2235,18 & 2235,18 & 2235,18 & 2235,18 & 2235,18 \\
\hline $\begin{array}{l}\text { Berat isi } \\
\text { basah } \\
\left(\mathrm{gr} / \mathrm{Cm}^{3}\right)\end{array}$ & 1,94 & 2,06 & 2,13 & 2,19 & 2,20 & 2,12 & 2,20 & 2,28 & 2,26 & 2,21 \\
\hline $\begin{array}{l}\text { Berat isi } \\
\text { kering ( } \mathrm{gr} / \\
\left.\mathrm{Cm}^{3}\right)\end{array}$ & 1,89 & 1,96 & 2,00 & 2,04 & 1,99 & 2,05 & 2,11 & 2,15 & 2,10 & 2,03 \\
\hline Z.A.V & 2,45 & 2,33 & 2,25 & 2,18 & 2,05 & 2,38 & 2,32 & 2.25 & 2,16 & 2,11 \\
\hline
\end{tabular}

Untuk pengujian berat isi dan kadar air secara spesifikasi keduanya telah memenuhi, tetapi hasilnya saja yang terjadi variasi. Variasi tersebut tidak terlalu berpengaruh pada pencapayan mutu yang hendak dicapai pada lapis pondasi bawah. Mutu yang ingin dicapai jelas akan tidak terwujud, jika persyaratan material tidak masuk kedalam batas ring (variasi) yang telah disyaratkan

Tabel 9 KadarAir Dan Perbandingan Lab. Dengan Pelaksana

\begin{tabular}{|c|c|c|c|c|c|c|c|c|c|c|}
\hline \multirow{2}{*}{$\begin{array}{l}\text { Kadar Air } \\
\text { Uraian }\end{array}$} & \multicolumn{5}{|c|}{ Lab } & \multicolumn{5}{|c|}{ Pelaks } \\
\hline & $\mathrm{I}$ & II & III & IV & $\mathrm{V}$ & $\mathrm{I}$ & II & III & IV & $\mathrm{V}$ \\
\hline $\begin{array}{l}\text { Berat tanah } \\
\text { basah + Cawan } \\
\text { (gr) }\end{array}$ & 123,96 & 108,88 & 104,89 & 110,17 & 148,91 & 126,20 & 73,90 & 135,20 & 85,40 & 74,30 \\
\hline $\begin{array}{l}\text { Berat tanah } \\
\text { kering + Cawan } \\
\text { (gr) }\end{array}$ & 121,09 & 104,35 & 99,25 & 102,95 & 135,66 & 123,20 & 71,30 & 129,20 & 80,10 & 69,20 \\
\hline $\begin{array}{l}\text { Berat cawan } \\
\text { (gr) }\end{array}$ & 10,39 & 10,34 & 10,16 & 9,69 & 10,15 & 3,00 & 2,60 & 5,50 & 5,30 & 5,10 \\
\hline $\begin{array}{l}\text { Berat air } \\
(\mathrm{gr})\end{array}$ & 2,87 & 4,53 & 5,65 & 7,22 & 13,25 & 32,50 & 11,20 & 34,40 & 9,50 & 9,60 \\
\hline $\begin{array}{l}\text { Berat tanah } \\
\text { kering (gr) }\end{array}$ & 110,71 & 94,00 & 89,09 & 93,26 & 125,51 & 90,70 & 60,10 & 95,30 & 70,60 & 59,60 \\
\hline Kadar Air & 2,59 & 4,82 & 6,34 & 7,74 & 10,56 & 3,31 & 4,33 & 5,77 & 7,51 & 8,56 \\
\hline
\end{tabular}


Tabel 10 Perbandingan Nilai CBR Laboratorium Dengan Nilai CBR Pelaksana

\begin{tabular}{|c|c|r|r|r|r|r|r|}
\hline Mould & Tumbuka & \multicolumn{2}{|c|}{ CBR Laboratorium (\%) } & \multicolumn{2}{|c|}{ CBR Pelaksana (\%) } & \multicolumn{2}{c|}{ Nilai Maksimum } \\
\cline { 3 - 7 } & & \multicolumn{1}{c}{$0,1^{\prime \prime}$} & $0,2^{\prime}$ & $0,1{ }^{\prime}$ & $0,2^{\prime}$ & CBR Lab & $\begin{array}{c}\text { CBR } \\
\text { Pelaksana }\end{array}$ \\
\hline I & $10 \mathrm{X}$ & 59,34 & 56,00 & 31,20 & 39,00 & 56,00 & 39,00 \\
\hline II & $35 \mathrm{X}$ & 66,64 & 62,23 & 54,60 & 57,85 & 62,23 & 57,85 \\
\hline III & $65 \mathrm{X}$ & 73,67 & 62,20 & 68,25 & 63,05 & 62,20 & 63,05 \\
\hline
\end{tabular}

Ternyata dari ketiga variasi tumbukan pada pengujian/pemeriksaan nilai CBR pada tabel 4.8 di atas, dapat dikatakan bahwa nilai CBR laboratorim lebih baik bila dibandingkan terhadap nilai CBR pelaksana. Juga dapat disimpulkan bahwa berdasarkan hasil pengujian keausan, proctor dan California Bearing Ratio mutu agregat hasil pengujian/pemeriksaan di laboratorium lebih baik bila dibandingkan hasil pengujian yang dilakukan oleh kontraktor pelaksana. Perbedaan tersebut dapat terjadi oleh karena beberapa faktor diantaranya perlakuan atau tingkat ketelitian kontraktor pelaksana yang kurang tepat.

\section{Kesimpulan dan Saran}

\subsection{Kesimpulan}

Berdasarkan hasil analisis dari data yang telah dilakukan, maka dapat disimpulkan sebagai berikut:

1. Dari hasil pemeriksaan yang telah dilakukan dilaboratorium dan oleh kontraktor pelaksana untuk pengujian sifat fisis agregat keduanya telah memenuhi persyaratan sesuai yang telah ditetapkan oleh Direktorat Jenderal Bina Marga. Adapun yang membedakan hanya pada variasi persen lolos saringan saja.

2. Nilai kehausan hasil pengujian laboratorium adalah $17,620 \%$, sedangkan nilai keausan hasil pengujian kontraktor pelaksana adalah 22,330\%. Dari hasil tersebut terlihat bahwa ketahanan material yang dilakukan dilaboratorim lebih baik bila dibandingkan yang dilakukan oleh pelaksana.

3. Berdasarkan hasil pengujian yang telah dilakukan pada penelitian ini, ternyata nilai CBR yang dilakukan di laboratorium Universitas Malikussaleh lebih baik (besar) nilainya bila dibandingkan yang telah dilakukan oleh kontraktor Pelaksana.

4. Dapat dikatakan bahwa mutu agregat hasil pemeriksaan yang dilakukan di laboratorium Universitas Malikussaleh lebih baik bila dibandingkan dengan mutu agregat hasil pemeriksaan yang dilakukan oleh kontraktor pelaksana.

\subsection{Saran dan Rekomendasi}

Dari uraian di atas maka dapat diberikan saran-saran sebagai bentuk rekomendasi sebagai berikut:

1. Perlu ketelitian dan pengalaman khusus saat melakukan pemeriksaan/pengujian material di laboratorim manapun agar mutu yang hendak dicapai dapat terlaksana sesuai yang diinginkan

2. Ikuti prosedur/petunjuk pelaksanaan dengan bijaksana saat melakukan pengujian di laboratorium. 


\section{Daftar Kepustakaan}

Departemen Pekerjaan Umum, 2010, Seksi 6.3 Spesifikasi Campuran Beraspal Panas, Direktorat Jenderal Bina Marga

Krebs, R.D., Walker, R.D., 1971, Highway Materials, Mc Graw Hill Inc., USA

Oglesby, C.H., R.G. Hick, 1982, Highway Engineering, $4^{\text {th }}$ ed. Willey and Sons, New York.

Sukirman, S., 1992, Perkerasan Lentur Jalan Raya, Penerbit Nova, Bandung

Sukirman, S., 1999, Perkerasan Lentur Jalan Raya, Penerbit Nova, Bandung

Bukhari, dkk, 2004, Rekayasa Bahan dan Tebal Perkerasan Jalan Raya, Bidang Studi Teknik Transportasi, Fakultas Teknik Universitas Syiah Kuala, Darussalam 